\title{
Siliceous microfossil distribution in the surficial sediments of Lake Baikal
}

\author{
E. F. Stoermer ${ }^{1}$, M. B. Edlund ${ }^{1}$, C. H. Pilskaln ${ }^{2}$ \& C. L. Schelske ${ }^{3}$ \\ ${ }^{1}$ Center for Great Lakes and Aquatic Sciences, University of Michigan, 2200 Bonisteel Blvd., Ann Arbor, MI \\ 48109-2099, USA \\ ${ }^{2}$ Department of Oceanography, University of Maine, Orono, ME 04469, USA \\ ${ }^{3}$ Department of Fisheries and Aquaculture, University of Florida, $7922 \mathrm{NW} 71^{\text {st }}$ Street, Gainesville, FL 32606 , \\ USA
}

Received 21 July 1994; accepted 11 December 1994

Key words: Russia, Lake Baikal, paleolimnology, diatoms, stomatocysts

\begin{abstract}
Examination of surficial sediments at 16 stations shows minor, but consistent differences in the numbers and kinds of siliceous microfossils deposited in different regions of Lake Baikal. There is a general north-south decreasing trend in total microfossil abundance on a weight basis. Endemic plankton diatom species are the most abundant component of assemblages at all stations. Chrysophyte cysts are present at all stations, but most forms are more abundant at northern stations. Non-endemic plankton diatom species are most abundant at southern stations. Small numbers of benthic diatoms and sponge spicules are found in all samples. Although low numbers are present in offshore sediments, the benthic diatom flora is very diverse. Principal components analysis confirms primary north-south abundance trends and suggests further differentiation by station location and depth.
\end{abstract}

\section{Introduction}

Lake Baikal is the world's deepest, and certainly one of the oldest continuously existing freshwater lakes. Its basin is part of the Baikal rift zone that extends from northwestern Mongolia to southeastern Siberia (Logtachev et al., 1974), with the latest phase of rifting thought to have begun c. 30-35 Ma (Lipman et al., 1989). The submerged portion of the Baikal depression is divided into three basins (Zorin et al., 1977). The southern basin has a maximum depth of approximately $1400 \mathrm{~m}$ and is divided from the deeper $(c .1600 \mathrm{~m})$ central basin by an underwater ridge that extends northeasterly across the lake in the Selenga Delta region. The central basin, in turn, is separated from the much shallower $(c .800 \mathrm{~m})$ northern basin by the Academician Ridge, which extends northwesterly from Ol'khon Island (Fig. 1). Each basin has active recent sedimentation (Edgington et al., 1991; Hutchinson et al., 1992). The sediment column is up to $7000 \mathrm{~m}$ thick and contains sediments of Neogene to recent age (Hutchinson et al., 1992). Thus, there is a high probability that the sediments of Lake Baikal contain a significant portion of the history of a geologically and climatically interesting part of the world. The study reported here is part of an effort (The Baikal Drilling Project) to recover and study this record. Its specific objectives are to determine current patterns of siliceous microfossil deposition in the lake, and if modern microfossil deposition has been grossly modified by anthropogenic effects. Because of its highly endemic flora, it is impossible to obtain external calibration sets for Lake Baikal. Investigations of large Pleistocene-age lakes have shown measurable anthropogenic effects, even in remote regions (Stoermer et al, 1990). In large lakes that have been subject to different degrees and histories of perturbation, there are large within-system differences in response, as measured by qualitative and quantitative changes in sedimentary siliceous microfossil assemblages (Stoermer et al., 1993). For these reasons, it is necessary to know what assemblages are being deposited under present conditions. If measurable regional differences are now present, they may 


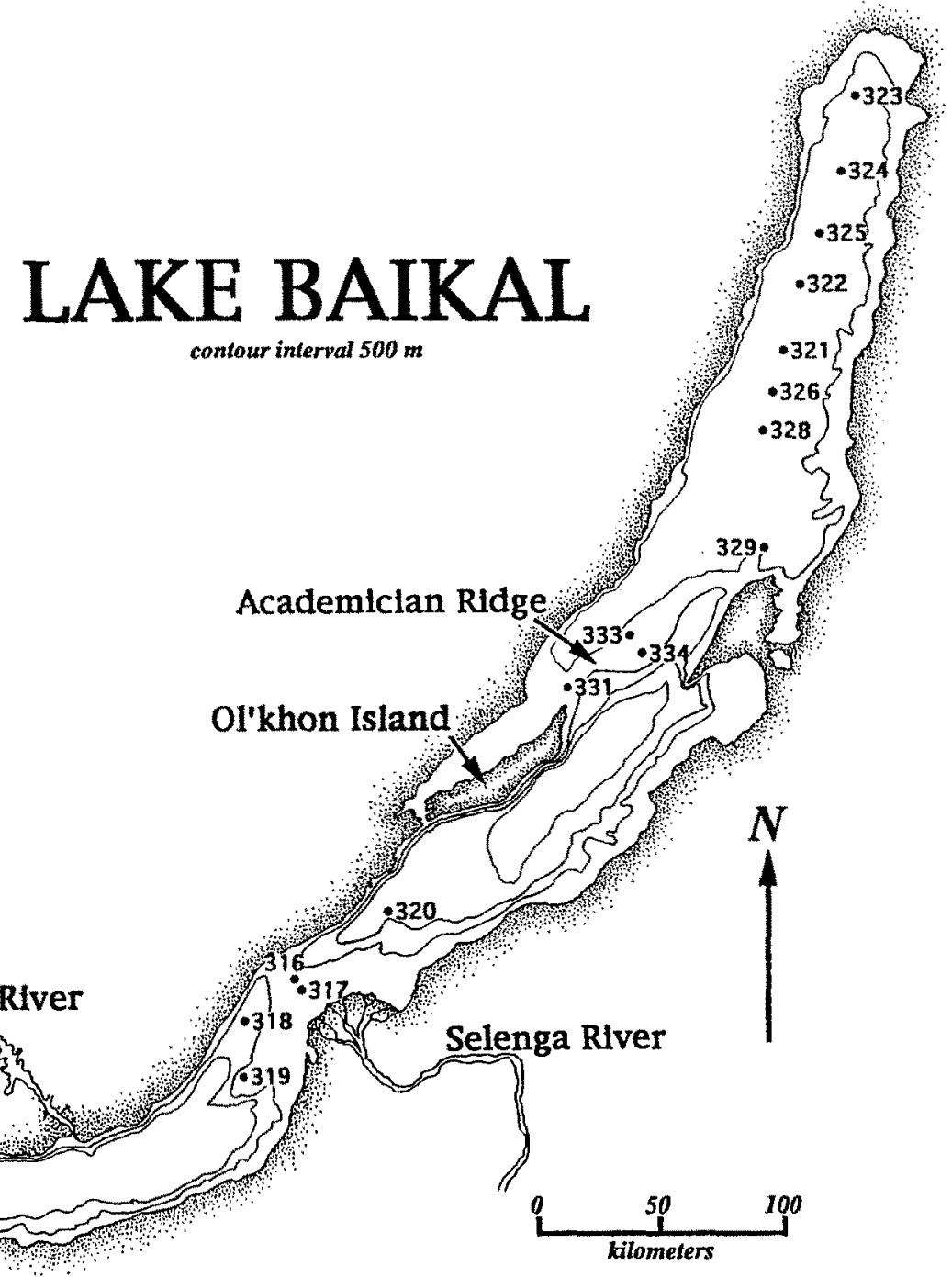

Fig. 1. Outline map of Lake Baikal, showing station locations.

provide a type of internal calibration valuable in interpreting past conditions.

Previous studies have indicated regional differences in phytoplankton abundance (Popovskaya, 1991). This work also suggests that concomitant differences in diatom species composition in different parts of Lake Baikal may be due to anthropogenic effects. Interpretations are complicated by very large inter-annual differences in timing and species composition of endemic diatom blooms. As in most other large northern lakes (Stoermer et al., 1981), Aulacoseira species are most abundant during cold periods of the year and Cyclotella species dominate the summer flora. In Lake Baikal, large abundance of endemic species occurs every several years, but Aulacoseira and Cyclotella species very rarely, if ever, bloom in the same year and rarely in successive years (Kozhov, 1963; Popovskaya, 1991). Possible limnological or climatic explanations of this periodicity have been put forth (Kozhov, 1955, 1963; Lund, 1966; Popovskaya, 1991), but no completely satisfactory explanation is apparent.

Based on short cores taken on cross-lake transects, Chernyaeva (1970) showed considerable qualitative differences in diatom assemblages deposited at different depths and distances from shore in the northern basin of Lake Baikal. Chernyaeva's findings differ significantly from a similar study of Lake Superior (Thay- 


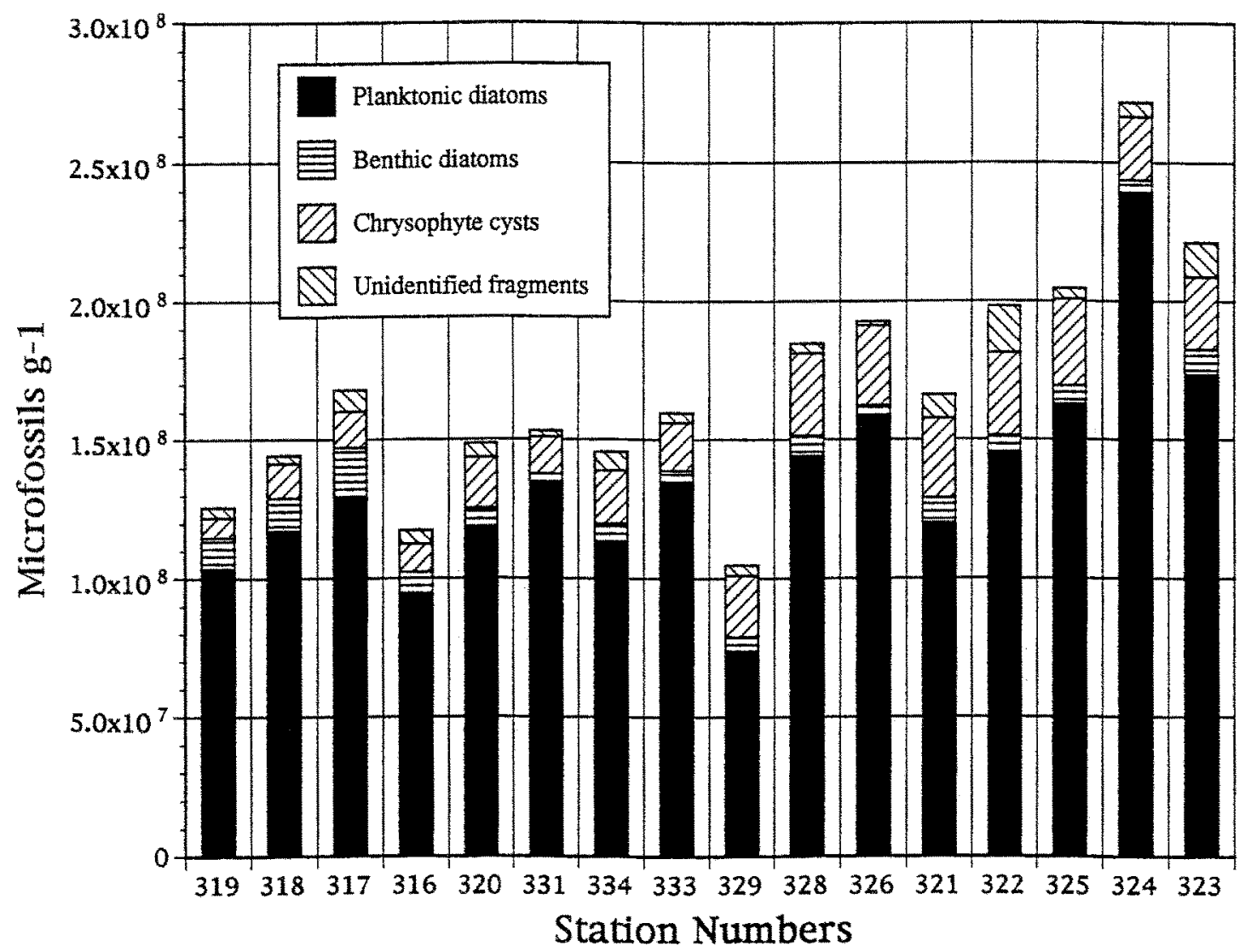

Fig. 2. Abundance (numbers $\mathrm{g}^{-1}$ dry wt. sediment) of different general groups of siliceous microfossils (identified in Figure Legend) in near-surface sediments of stations sampled in Lake Baikal (see Fig. 1). Stations are arranged in approximate geographic order, from south (right) to north (left).

er et al., 1983) in two respects. Diatoms are absent from surficial sediments in large areas of Lake Superior. In this large lake, which dates only to late Pleistocene, siliceous microfossils appear to be deposited and preserved only in profundal basins and some marginal basins. In Lake Baikal, it appears that diatoms are preserved in sediments on marginal slopes as well as in profundal basins. It also appears that there is greater regional difference in diatom species composition in Lake Baikal than in Lake Superior, although this is difficult to state firmly on the basis of only two studies. Comparison of Chernyaeva's (1970) study with short cores from Lake Superior (Stoermer et al., 1985a) also suggests that diversity is differently expressed in the two systems. The minor elements of benthic diatom communities preserved in cores from both lakes are very diverse, but appear to be more diverse in Lake Baikal than in Lake Superior. This conjecture is supported by studies of the modern benthic diatom floras (Skvortzow \& Meyer, 1928; Stoermer, 1975; Stoer- mer et al, 1986; Foged, 1993). On the other hand, the plankton flora of Lake Baikal, at least elements that leave sedimentary remains, appears less diverse than similar assemblages in Lake Superior.

\section{Materials and methods}

Samples analyzed consist of homogenized splits of the top $1 \mathrm{~cm}$ section of short cores from the sites shown in Figure 1. Samples were taken by CHP as part of a USGS-funded geochemical study, the partial results of which are reported elsewhere (Pilskaln, 1992). Splits of these samples used for diatom analyses were freezedried so that accurate weights could be obtained and to prevent specimen breakage sometimes associated with air-drying of fine grained sediments. The sediments were cleaned according to the following protocol:

1. Weigh $12-15 \mathrm{mg}$ of freeze-dried material into $200 \mathrm{ml}$ tall form beakers. 


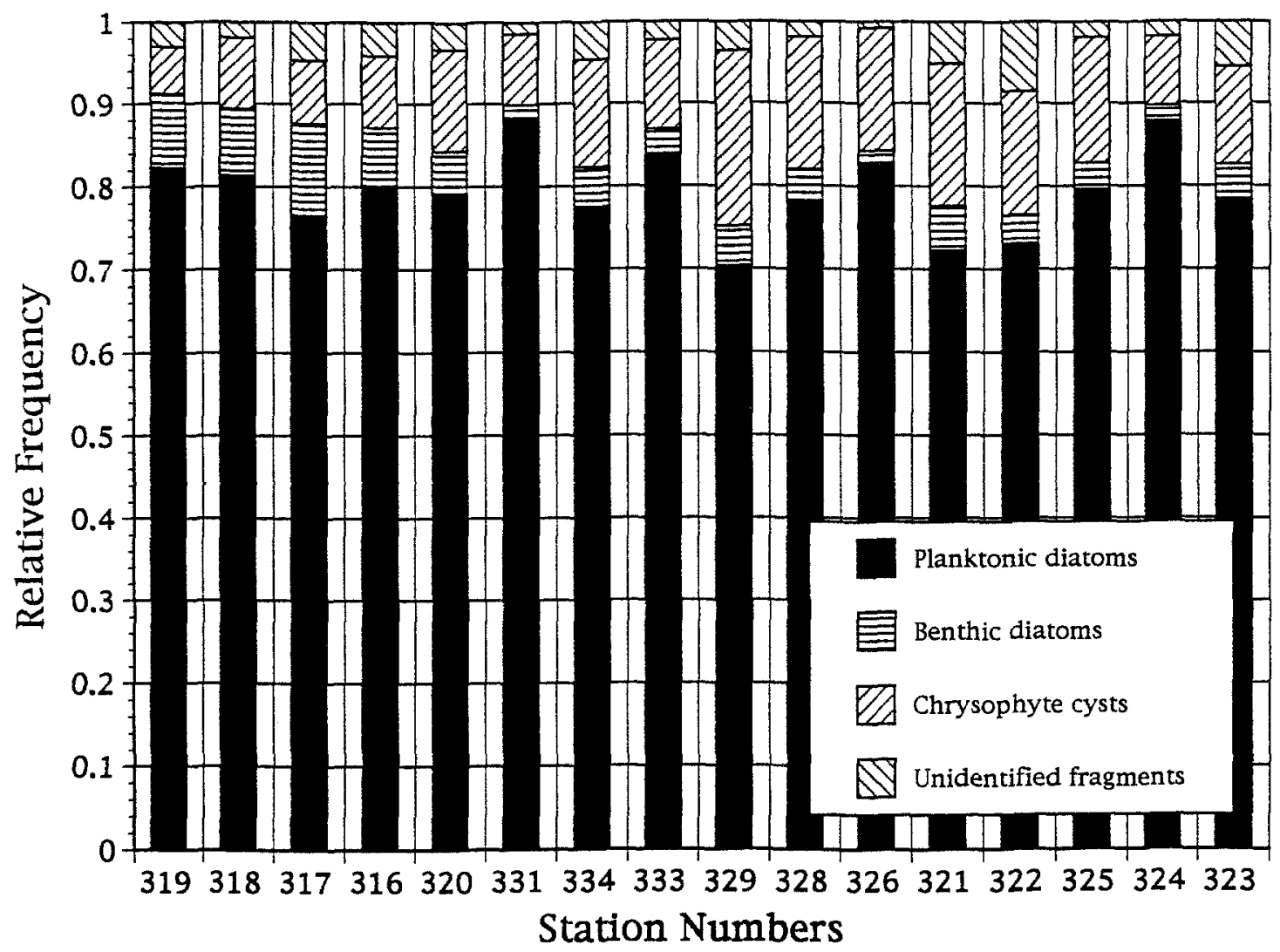

Fig. 3. Relative abundance of different general groups of siliceous microfossils (identified in Figure Legend) in near-surface sediments of stations sampled in Lake Baikal (see Fig. 1). Stations are arranged in approximate geographic order, from south to north.

2. Add $20 \mathrm{ml}$ of $30 \% \mathrm{H}_{2} \mathrm{O}_{2}$ and heat to slow boil (c. $110^{\circ} \mathrm{C}$ ) for $30 \mathrm{~min}$.

3. Slowly add $25 \mathrm{ml}$ concentrated $\mathrm{HNO}_{3}$. This results in a rapid reaction that subsides in $c$. four min.

4. After rapid reaction is complete, allow sediment acid suspension to fume $\left(c .120^{\circ} \mathrm{C}\right)$ for one hr.

5. Remove from heat and allow to cool.

6. Wash material by settling and decantation six times in distilled water to remove acid and oxidation byproducts.

Material suspended in distilled water is placed in chambers similar to those designed by Battarbee (1973). Water is allowed to evaporate in a covered chamber, isolated from vibration. Settling chambers used accept four $18 \mathrm{~mm}$ round \#1 covers $(0.18 \mathrm{~mm}$ nominal thickness), thus 4 replicate sub-samples are potentially available from each sample.

After air drying, covers are removed from chambers, heated to c. $200{ }^{\circ} \mathrm{C}$ for $30 \mathrm{~min}$ to remove any capillary water, and mounted in Hyrax ${ }^{T M}$. Before mounting, material on cover glasses is examined in oblique light to detect any gross irregularities in distribution of material. Prepared slides are again examined under low power to detect any gross departures from random distribution of material.

Siliceous microfossils were enumerated on one $18 \mathrm{~mm}$ transect on each of two prepared slides from each sample, resulting in two replicate abundance estimates. All specimens and fragments of specimens identifiable as biogenic are enumerated (Glover, 1982; Stoermer et al., 1985b). Fragments that can be assigned to a taxon with reasonable confidence, regardless of absolute size, are included in the category and mathematically 'reconstituted' and reported in terms of whole valves and fractions. Fragments lacking morphological characteristics allowing identification, or simply too small to contain such features, are reported as unidentified. In this study, the unidentified category consists almost entirely of unidentified diatom fragments.

Due to the high apparent diatom content of Lake Baikal sediments, biogenic silica was measured inde- 


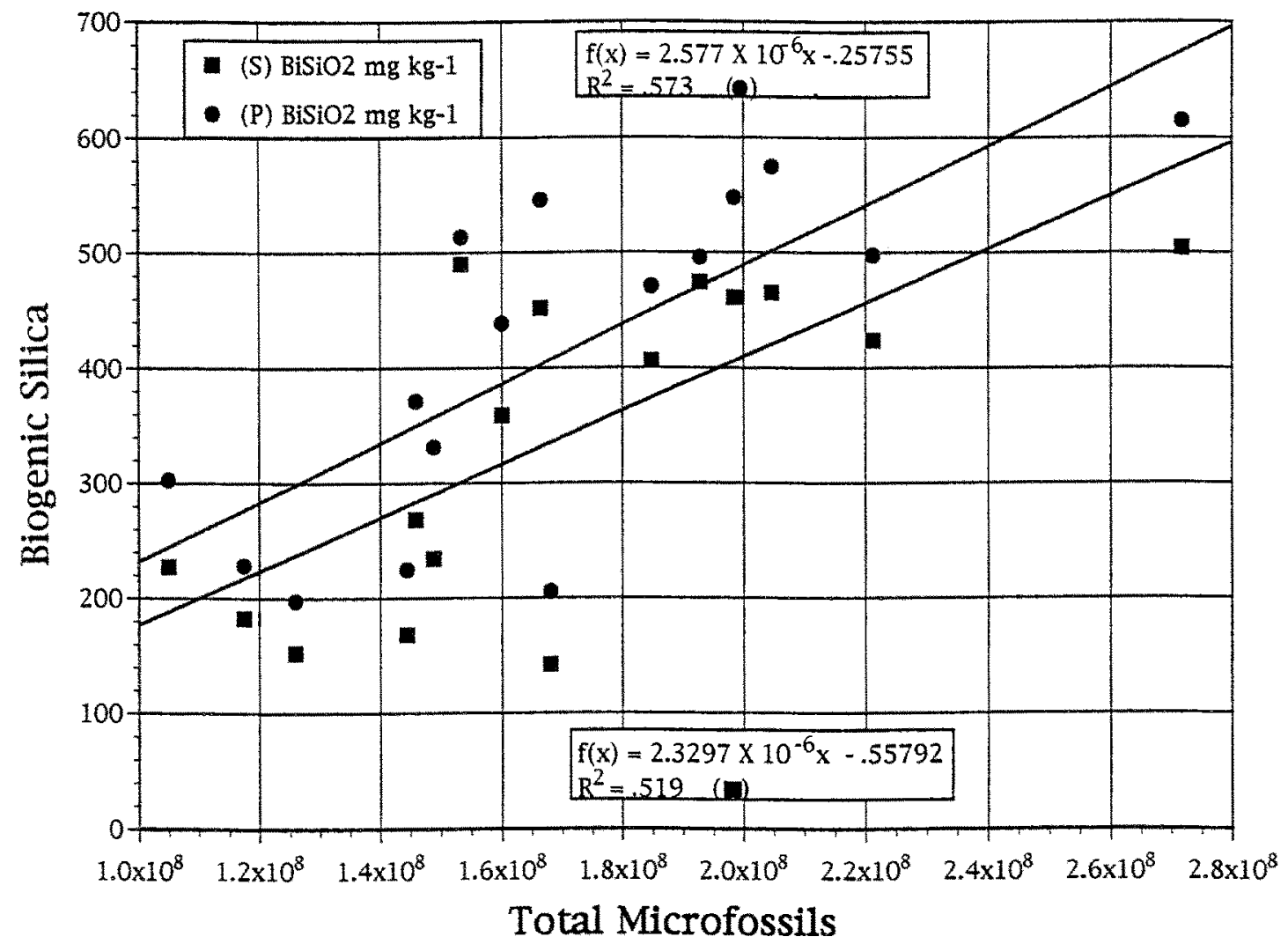

Fig. 4. Relation of siliceous microfossil numbers to chemically determined biogenic silica at stations sampled in Lake Baikal. Silica was measured by two methods (labeled and $\mathbf{-}$ - see text). Upper line is fitted to samples and upper equation refers to this fit. Lower line is fitted to samples and lower equation refers to this fit.

pendently in two laboratories by two methods. Measurements made in Schelske's laboratory used extraction methods originally developed by DeMaster (1981) and modified by Krausse et al. (1983). Measurements made in Pilskaln's laboratory used extraction methods (Pilskaln \& Paduan, 1992) adapted from Leinen (1977), Eggimen et al. (1980), and Mortlock \& Froelich (1989). The major difference in these methods is that the latter uses double the concentration of $\mathrm{Na}_{2} \mathrm{CO}_{3}$. In both cases silica concentration was measured spectrophotometrically using the molybdate blue method.

\section{Results}

The abundance of siliceous microfossils per g dry weight sediment, and the contribution of major microfossil groups, is shown in Fig. 2. All identifiable siliceous biological remains are included, although sponge spicules are not plotted because their num- bers are too low to be adequately represented on the graph. Although the numbers of sponge spicules are low, because of their size and solid construction, they could possibly contribute an appreciable fraction of biogenic silica (Conley \& Schelske, 1993). There is a general decreasing north-south trend in values, interrupted by notably low values at stations 316 and 329 . Planktonic diatoms are the most abundant microfossils at all stations (Fig. 2). Their relative frequency (Fig. 3) ranges from $88.1 \%$ to $70.4 \%$ of assemblages. Chrysophyte cysts are the second most abundant group (Fig. 2) and show a small general north-south trend in abundance. Chrysophyte cysts are proportionally more abundant at mid-lake stations and constitute slightly smaller portions of assemblages at stations in the northern and, particularly, southern regions of Lake Baikal. Relative frequencies range from $21.2 \%$ at station 329 to $5.7 \%$ at station 319 (Fig. 3). Chrysophyte remains other than cysts are very rare in the collections analyzed. Benthic diatoms constitute a very diverse, but numerically minor, fraction of assemblages at all sta- 


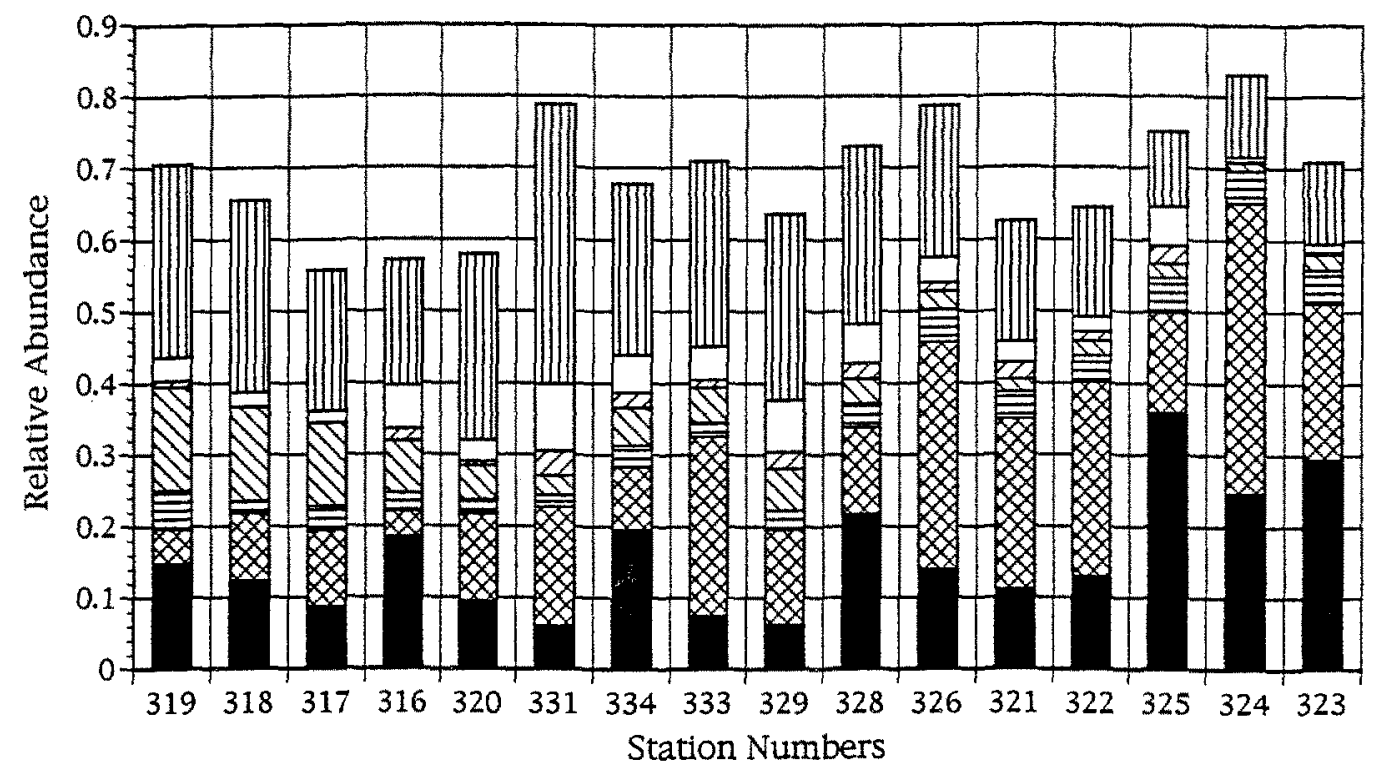

$\square$ Cyclotella minuta
$\square$ cyclotella ornata
$\square$ cyclotella baicalensis
Aulacoseira sp. "spore"

Fig. 5. Relative abundance of dominant endemic planktonic diatom taxa in near-surface sediment at stations sampled in Lake Baikal.

tions (Fig. 3). Relative frequencies range from $1.8 \%$ at station 331 to $11.1 \%$ at station 317 , and are generally higher at stations south of the Selenga Delta. The numbers of unidentified diatom fragments range from $8.5 \%$ at station 322 , to $0.3 \%$ at station 326 , and there is no apparent regional trend in the abundance or proportion of small fragments across stations.

Siliceous microfossil abundance and chemically determined biogenic silica are reasonably well correlated (Fig. 4). The more rigorous digestion procedure (labeled ' $\mathrm{P}$ ' in Figure 4) yielded higher (ave. 19.1\%) estimates, and were slightly better related to numerical estimates of microfossil abundance (Fig. 4). In general, stations in the northern part of the lake contain more biogenic silica per unit mass of sediment than those in the south. It should be noted, however, that there are two reasonably distinct groups of stations: one consisting of all samples from stations south of Academician Ridge plus stations 334 and 329 , and the other consisting of the remaining stations north of Academician Ridge.
Assemblages at all stations are dominated by a few planktonic taxa endemic to Lake Baikal (Fig. 5). These entities comprise more than $50 \%$ of all siliceous microfossils enumerated in all samples. Since there are differences of opinion concerning circumscription of these taxa, a few words of explanation regarding our concept of their limits is perhaps appropriate here. Although we enumerated and have plotted three morphotypes of Aulacoseira baicalensis in Fig. 5, as the plot illustrates, our results do not support any meaningful taxonomic separation within this species. Although these were considered formae by Skvortzow (1937), in our opinion the morphological differences noted are ecophenotypic and likely analogous to differences in A. islandica morphology in the Laurentian Great Lakes (Stoermer et al., 1981; 1985c). We enumerated Cyclotella ornata separately from $C$. baicalensis and $C$. minuta. Our observations fully support Flower's (1993) conclusion that these morphological entities are all separate taxa. The taxon we report as Aulacoseira sp. 'spore' has been considered a sporangial frustule of A. baicalensis by some authors (Skvortzow, 1937: pl. 1, 


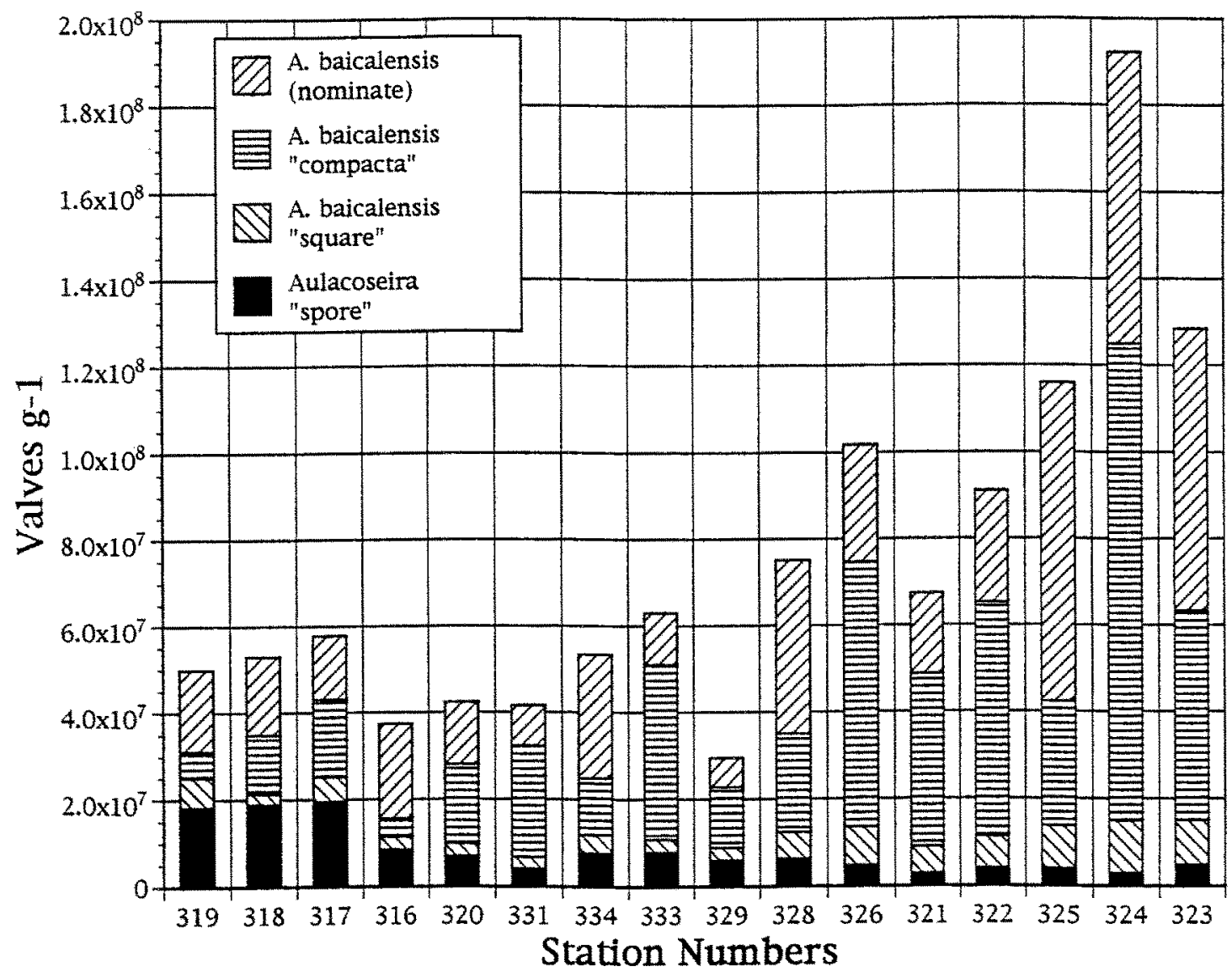

Fig. 6. Abundance (valves $\mathrm{g}^{-1}$ ) of most common Aulacoseira morphotypes in near-surface sedinents of stations sampled in Lake Baikal.

Figs 6\&7), or a separate morphotype of A. islandica (Genkal \& Popovskaya, 1991: Fig. 1). In our opinion, its systematic affinities are uncertain, hence we prefer to retain the arbitrary designation.

The absolute abundance of $A$. baicalensis is highest at northern stations, with a generally decreasing trend southward (Fig. 6). Abundance of this species, in accord with total microfossil abundance (Fig. 2), is notably low at stations 316 and 329 . There is a slight increase in abundance of $A$. baicalensis at the three most southern stations. Abundance of dominant Cyclotella species is shown in Fig. 7. Both in total and individually, they are most abundant at stations in the mid-portion of the lake and less abundant at stations in both the north and south regions. Total abundance of these species is slightly higher in samples from stations at the extreme southern end than at stations in the extreme north.

The most common chrysophyte cyst morphotype, cyst 1 (Fig. 8 - top) is most abundant in samples from stations in northern regions of the lake. Other reason- ably abundant cyst types (Fig. 8 - bottom) have similar, but less strongly differentiated distribution patterns. Although a large number (75) of cyst morphotypes were noted, most are rare, occurring singly or only in a few samples.

Several small centric diatoms that are often associated with eutrophic conditions are either most abundant, or were found exclusively at stations in the southern part of the lake. Cyclostephanos cf. dubius (Fig. 9) was noted at only one station (333) north of the Academician Ridge and is most abundant at station 317 , near the Selenga Delta. Stephanodiscus cf. parvus (Fig. 9) occurs at only two stations north of the Academician Ridge and is also most abundant in sediments from station 317. Stephanodiscus cf. hantzschit (Fig. 9) and S. binderanus (Fig. 9) occurred in detectable quantities at stations throughout the lake, but were strikingly more abundant at stations south of the Academician Ridge.

Most of the araphid pennate diatoms that occurred in detectable abundance also tended to follow the above 


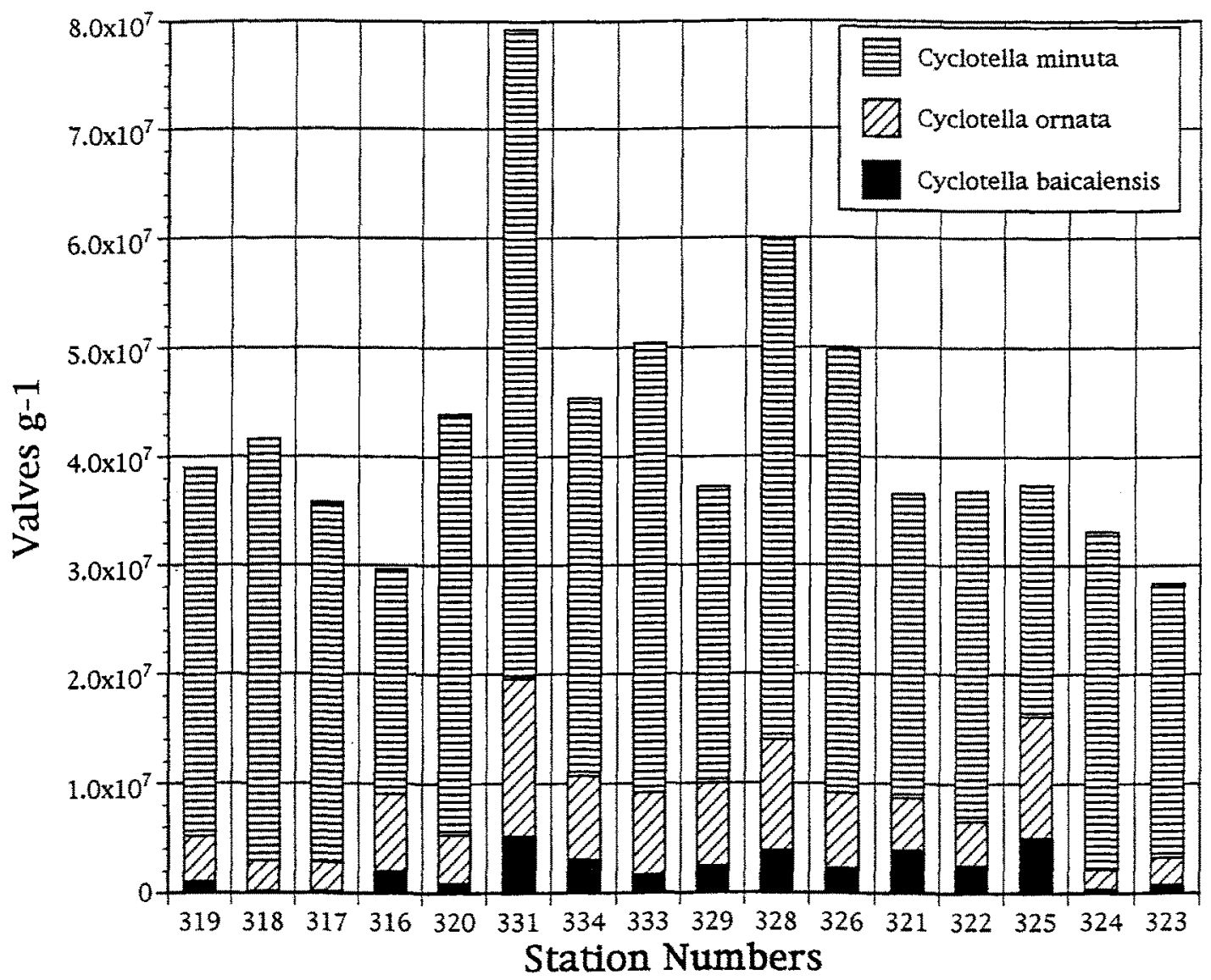

Fig. 7. Abundance (valves $\mathrm{g}^{-1}$ ) of most common Cyclotella morphotypes in near-surface sediments of stations sampled in Lake Baikal.

distribution pattern (Fig. 10). Included in this group are Synedra cf. acus, S. cf. ulna var. danica, and S. cf. delicatissima, all primarily planktonic species, and Staurosirella cf. pinnata, a primarily benthic species that is commonly entrained into plankton associations.

Principal components analysis based on absolute abundance of major taxa (Fig. 11) divides stations into two major groups: one consisting of stations closest to the Selenga Delta $(316,317,318$, and 320$)$, and one consisting of northern stations. If stations are clustered according to relative abundance of major species (Fig. 12), a more complex pattern is produced. Stations 323-325, from the far northern part of the lake, are grouped as are stations $317-319$, the southerly most stations sampled. Another group of stations $(320,329$, 331) are also grouped. Their main distinguishing geographical characteristic is that they occur towards the margins of depositional basins. Other samples from stations north of the Academician Ridge are grouped, with some sub-grouping according to geographical proximity $(321,322,326 ; 328,333,334)$. The sam- ple from station 316 is placed with the latter group, outside its geographic context. Assemblage characteristics shared by these stations that apparently produce this grouping are relatively high numbers of benthic diatoms and relatively high abundance of some chrysophyte cyst morphotypes.

\section{Discussion}

It needs to be emphasized that Lake Baikal sediments consist of an unusually large fraction of siliceous biological remains. Because most of the planktonic diatom species endemic to Lake Baikal are large, robustly silicified forms, microfossil numbers are not directly comparable to assemblages found in most post-Pleistocene lakes. Chemically determined biogenic silica values are also high, and our results indicate that more rigorous leaching may be necessary to assure recovery. Results also indicate that the difference between biogenic silica values obtained by the two methods tested 


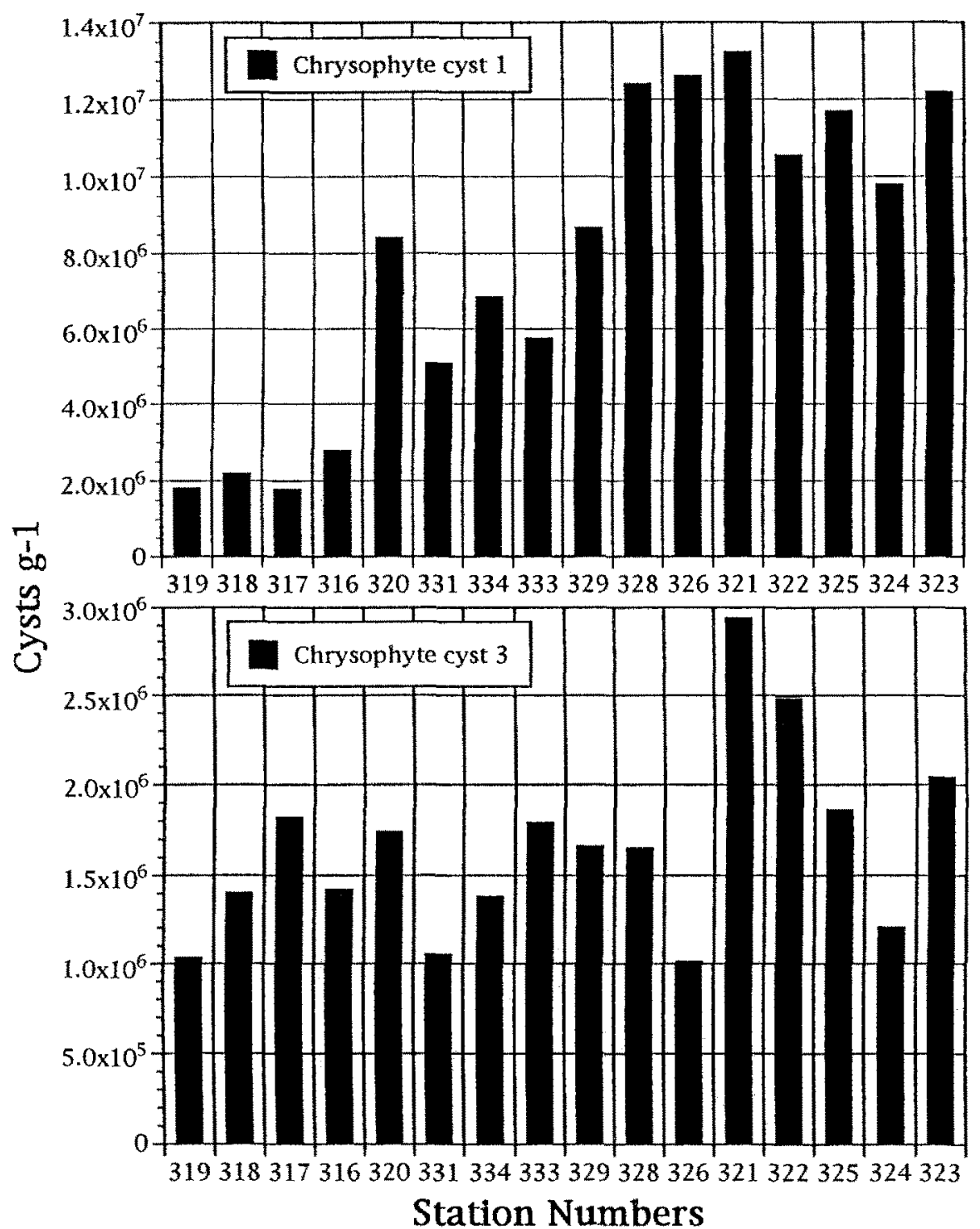

Fig. 8. Abundance (cysts $\mathrm{g}^{-1}$ ) of two most common chrysophyte cyst morphotypes in near-surface sediments of stations sampled in Lake Baikal. Taxa are identified in Figure legends.

is not constant for all samples. It thus appears that there are factors other than the gross abundance of siliceous microfossils controlling biogenic silica yield.

The most outstanding characteristic of siliceous microfossil assemblages from Lake Baikal is the extreme degree of endemism. So far as the diatom flora is concerned, endemic plankton species completely dominate the flora at all stations sampled. Significant quantities of apparently non-endemic diatom species occur only at southern stations. Although these taxa resemble forms found in European lakes, their morphology has not been thoroughly investigated with
SEM or genetic techniques, and the possibility remains that they may also be unique to Lake Baikal. Considering the species involved, if we assume they are the same, or ecologically similar to European forms, their occurrence can be interpreted as indicative of a higher state of eutrophication at southern stations. Whether this results from the natural influences of nutrient loads from the Selenga River, or if it results from local anthropogenic effects, or some combination of the two, cannot be satisfactorily addressed on the basis of results from this study. Previous studies by Chernyaeva (1970) favor anthropogenic effects as the 

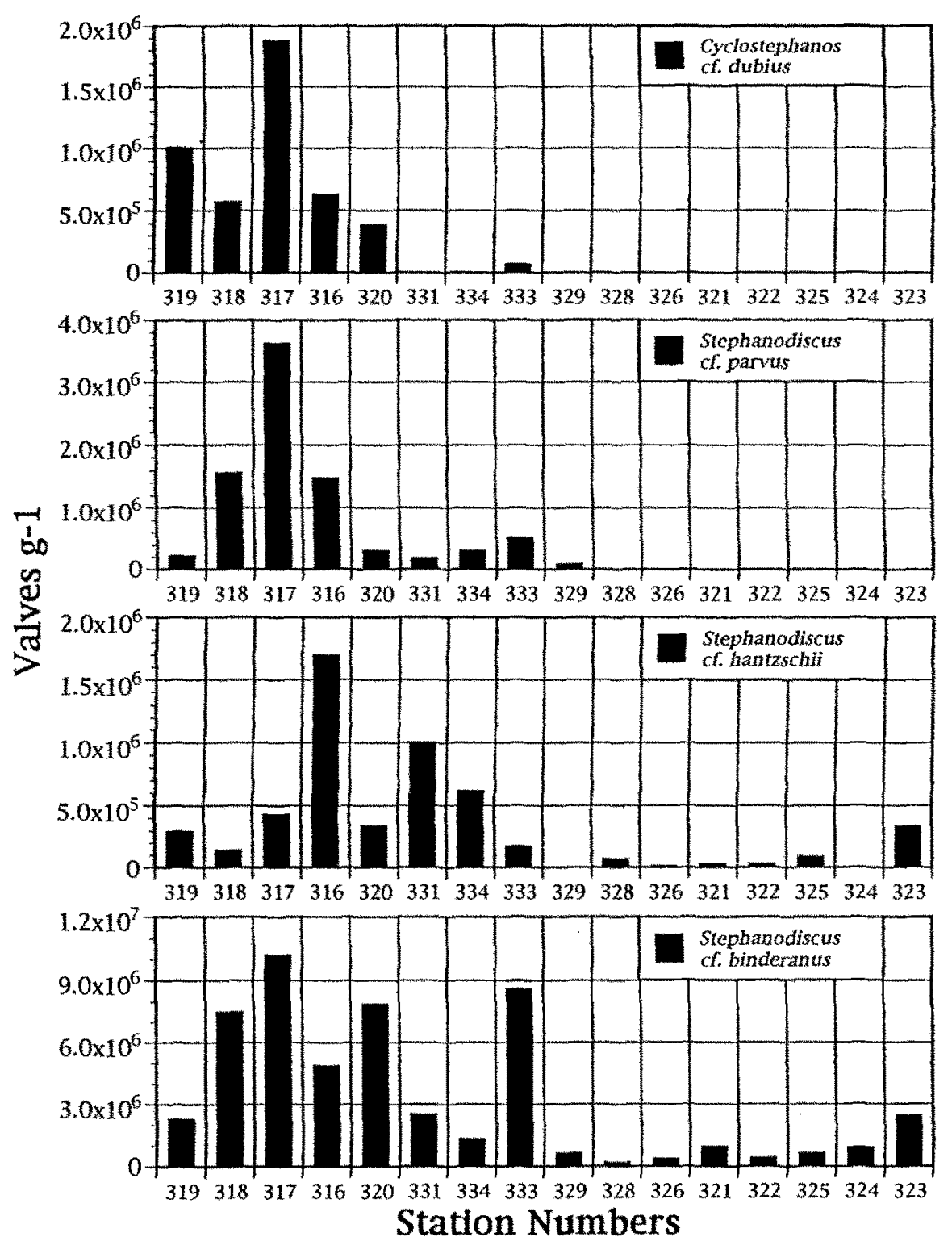

Fig. 9. Abundance (valves $\mathrm{g}^{-1}$ ) of most common Cyclosteptamos and Stephanodiscus morphotypes in nearusurface sediments of stations sampled in Lake Baikal. Taxa are identifed in Figure Legends. Station numbers are given at the bottom of each panel.

most plausible explanation. Detailed comparisons of cores from the regions of interest will help to resolve the relative importance of anthropogenic effects.

Another striking characteristic of diatom assemblages deposited in the near surface sediment of Lake Baikal is lack of diversity amongst planktonic species. It appears that, contrary to Hutchinson's (1961) often quoted paradox of the plankton, competitive exclusion has reduced the number of planktonic diatom species in Lake Baikal to a few entities successfully evolved to the particular requirements of existence in this unusual habitat. According to our observations (unpublished), the same could be said about Lake Malawi, Lake Ochrid, and probably other large ancient lakes of the world. From our results, it appears that increased richness of planktonic species can be viewed as evidence of disturbance in Lake Baikal. It is important to stress that this statement applies to planktonic species only. The benthic diatom flora represented in our cores is exceedingly diverse, but numbers of benthic taxa are so low it would be necessary to conduct a special study 

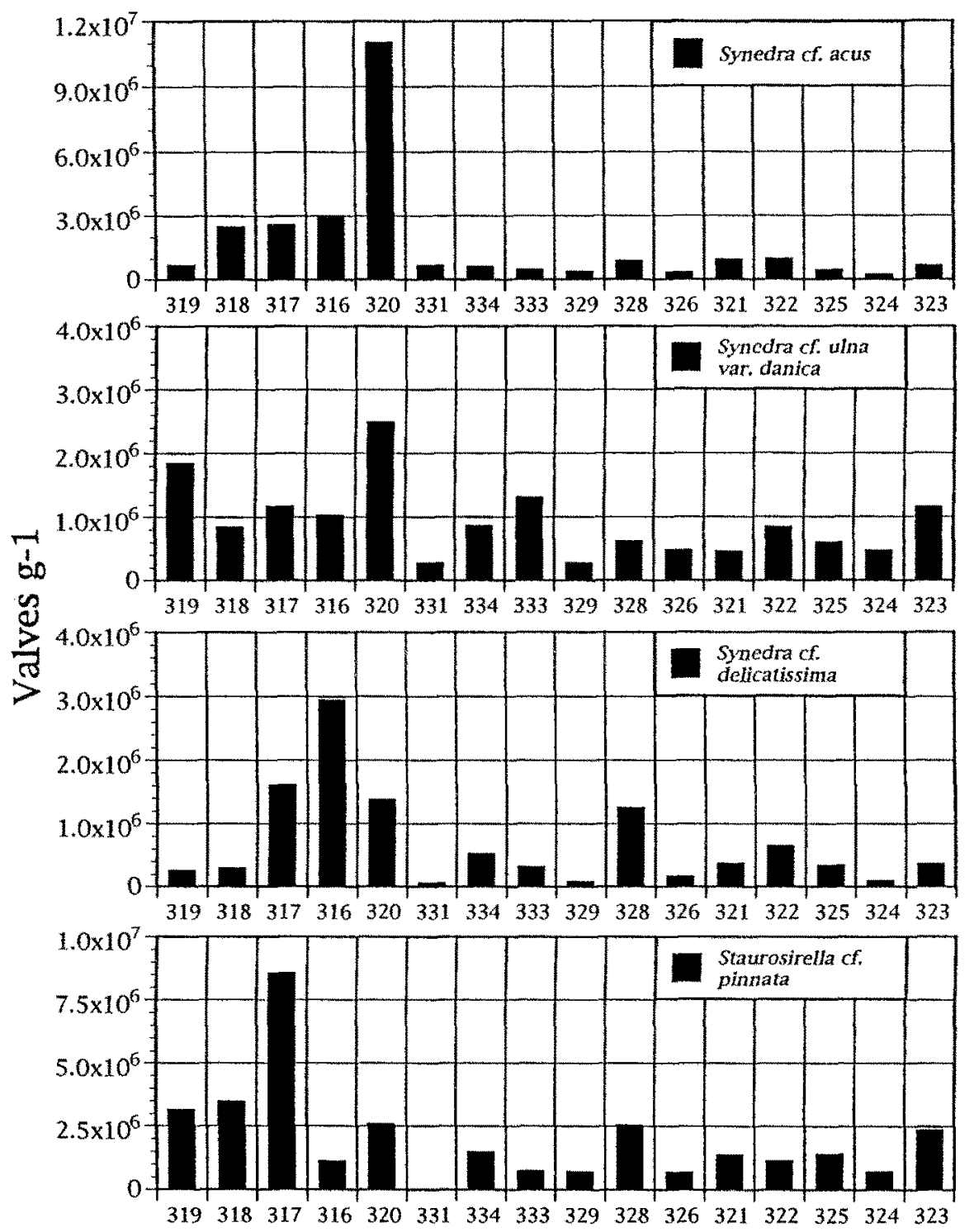

Station Numbers

Fig. 10. Abundance (valves $\mathrm{g}^{-1}$ ) of other non-indigenous planktonic diatom morphotypes in near-surface sediments of stations sampled in Lake Baikal. Taxa are identified in Figure Legends. Station numbers are given at the bottom of each panel.

in order to address trends on benthic populations effectively.

Our study shows differences in siliceous microfossil assemblages in different parts of Lake Baikal. The major difference in overall abundance trends is from high numbers in northerly stations to generally lower numbers in southerly stations. It should be understood that this trend is in sediment composition, which is a function of production, preservation, and dilution by allochthonous material. No microscopically discernible differences in preservation are evident in the material we examined. Preservation is good to excellent at all stations. Based on results of biogenic silica analyses (Fig. 4) and estimates of sedimentation rates (Edgington et al., 1991; Williams et al, 1993; Granina et al., 1993), it appears that sedimentation is considerably more rapid at southern stations. If these estimates are accepted, annual flux of diatom remains to the sediments, the best estimator of production, is actually highest at southern stations, but siliceous microfossil abundance in sediments is diluted by higher allochthonous sedimentation. Some stations 


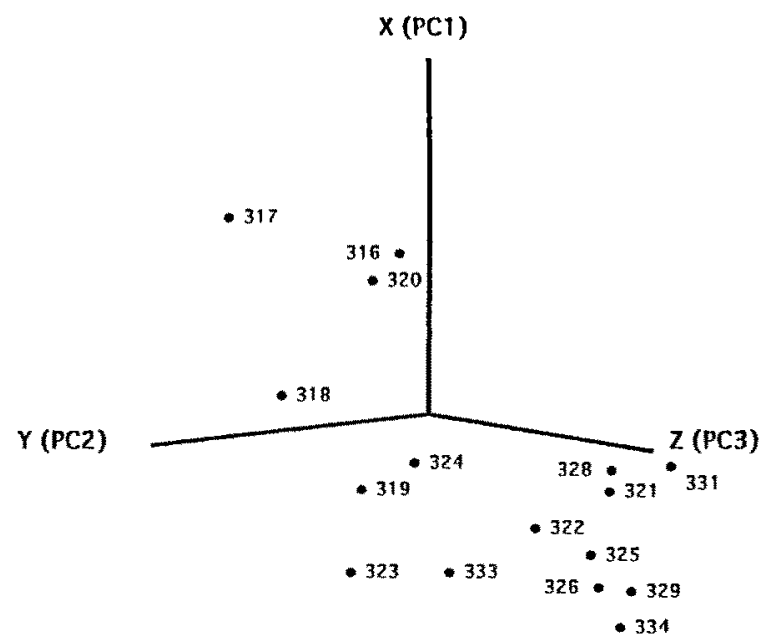

Fig. 11. Principal components analysis of siliceous microfossil assemblages found in near-surface samples from Lake Baikal stations based on absolute abundance.

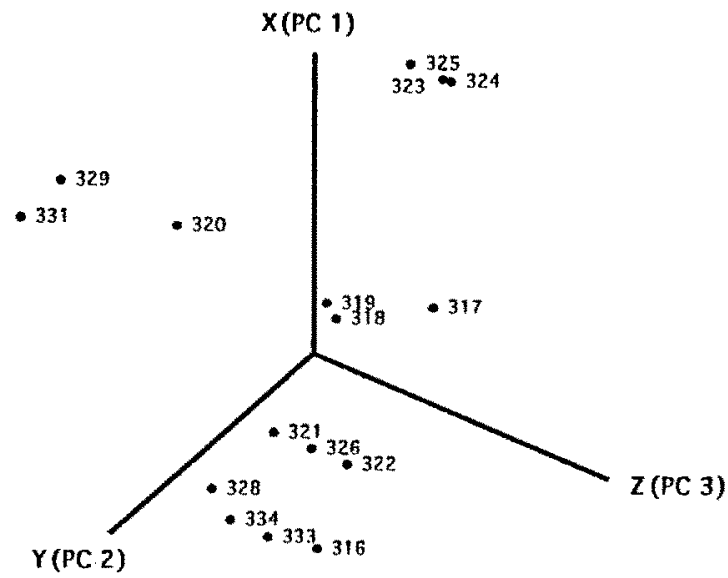

Fig. 12. Principal components analysis of siliceous microfossil assemblages found in near-surface samples from Lake Baikal stations based on relative abundance.

are apparently more affected by within-basin position than by north-south differences. Station 329 , in particular, is not classified with its nearest geographical neighbors in either the biogenic silica plot (Fig. 4) or in a PCA based on relative species abundance (Fig. 12). We interpret this to indicate small differences in siliceous microfossil composition and abundance between stations on the margins of basins, compared to stations more central to a given basin. Plausible factors that might give rise to such differences include greater relative abundance of benthic species nearest to nearshore production areas, relatively greater nutrient loading of nearshore waters, and the effects of strong coastal thermal fronts, characteristic of large, northern lakes
(Lorefice \& Munawar, 1974; Shimaraev et al., 1993). These effects on the sedimentary diatom assemblage are small, and are not well resolved by the samples available to our present study.

Our study thus indicates that there are measurable differences in abundance and composition of surface sediment diatom assemblages in different regions of modern Lake Baikal. Although quantitative differences are small, some species appear to be restricted to certain parts of the lake. Most such taxa appear to be recent introductions (Chernyaeva, 1970; Edlund et al., submitted), although some, notably Synedra acus, are present in samples from pre-European strata (Bradbury et al., 1994). We infer that occurrence of a number of these non-indigenous species in the southern region of Lake Baikal is a first response to environmental modification. This, in turn, implies that Lake Baikal is a very sensitively poised system, that should be responsive to small changes in regional conditions as they affect nutrient loading to the lake and physical factors which affect distribution of external nutrient loads within the lake. Examples of the latter factors include extent of winter ice cover, duration and completeness of circulation, and range of surface water temperatures.

In terms of future down-core interpretations, the apparent sensitivity of the modern Lake Baikal system indicates that sedimentary diatom assemblages offer a wonderfully sharp tool for interpreting past environmental changes. Like all sharp tools, this approach should be used cautiously and intelligently. It is clear that species replacements can take place in one basin of the lake due to very modest changes in external forcing factors. Indeed, biotic communities may be sensitive to physical and chemical changes which are practically unquantifiable with current measurement technology. Hence, some changes in diatom assemblages may be difficult to correlate with conventionally measured water chemistry.

Based on our results, composition of siliceous microfossil assemblages is also sensitive to position of a particular sampling site within a given sedimentation basin. This may be a significant confounding factor for ecological interpretation in an ancient lake, where basin morphometry has been modified by tectonic forces during its history. However, this sensitivity may also offer a novel tool for detecting changes in basin morphometry. 


\section{Acknowledgments}

We thank Jenny Paduan for sample analysis and Donna Francis for help in preparing illustrations. Collection of the material used in this investigation was supported by the U.S. Geological Survey, the Russian Limnological Institute (Irkutsk, Russia), and National Geographic Research Grant 4272-90 to CHP. Sample analysis was supported by NSF Grant EAR 9119537. This study is contribution No. 568 from the Center for Great Lakes and Aquatic Sciences, University of Michigan.

\section{References}

Battarbee, R. W., 1973. A new method for estimating absolute microfossil numbers with special reference to diatoms. Limnol. Oceanogr. 18: 647-653.

Bradbury, J. P., Ye. V. Bezrukova, G. P. Chernyaeva, S. M. Colman, G. Khursevich, J. W. King \& Ye. V. Likoshway, 1994. A synthesis of post glacial diatom records from Lake Baikal. J. Paleolimnol. 10: 213-252.

Chernyaeva, G. E., 1970. Diatoms in the bottom sediments of northern Lake Baikal. pp. 144-160. In: Bottom Deposits of Baikal, Academy of Sciences, Moscow. (in Russian)

Conley, D. J. \& C. L. Schelske, 1993. Potential role of sponge spicules in influencing the silicon biogeochemistry of Florida lakes. Can. J. Fish. aquat. Sci. 50: 296-302.

DeMaster, D. J., 1981. The supply and accumulation of silica in the marine environment. Geochim. Cosmochim. Acta 45: 1715 1732.

Edgington, D. N., J. V. Klump, J. A. Robbins, Y. S. Kusner, V. D. Pampura \& I. V. Sandimirov, 1991. Sedimentation rates, residence times and radionuclide inventories in Lake Baikal from ${ }^{137} \mathrm{Cs}$ and ${ }^{210} \mathrm{~Pb}$ in sediment cores. Nature 350: 601-604.

Edlund, M. B., E. F. Stoermer \& C. H. Pilskaln, submitted. Siliceous microfossil succession in the recent history of two basins in Lake Baikal. J. Paleolimnol.

Eggimen, D. W., F. T. Manheim \& P. R. Betzer, 1980. Dissolution and analysis of amorphous silica in marine sediments. J. Sediment. Petrol. 50: 215-225.

Flower, R. J., 1993. A taxonomic re-evaluation of endemic Cyclotella taxa in Lake Baikal, Siberia. Nova Hedwigia, Beih. 106: 203 220.

Foged, N., 1993. Some diatoms from Siberia, especially from Lake Baikal. Diatom Res. 8: 231-279.

Genkal, S. I. \& G. I. Popovskaya, 1991. New data on the frustule morphology of Aulacosira islandica. Diatom Res. 6: 255-266.

Glover, R. M., 1982. Diatom fragmentation in Grand Traverse Bay, Lake Michigan and its implications for silica cycling. Doctoral Dissertation, University of Michigan, Department of Atmospheric and Oceanic Sciences, $282 \mathrm{pp}$.

Granina, L. Z., M. A. Grachev, E. B. Karabanov, V. M. Kuptsov, M. K. Shimaraeva \& D. F. Williams, 1993. Accumulation of biogenic silica in bottom sediments of Baikal. Geologiya i Geofizika 34: 126-135.

Hutchinson, D. R., A. J. Golmshtok, L. P. Zonenshain, T. C. Moore, C. A. Scholz \& K. D. Klitgord, 1992. Depositional and tectonic framework of the rift basins of Lake Baikal from multichannel seismic data. Geology 20: 589-592.
Hutchinson, G. E., 1961. The paradox of the plankton. Am. Nat. 95 : 137-146.

Kozhov, M. M., 1955. Seasonal and annual variation in the plankton of Lake Baikal. Proc. All Union Hydrobiol. Soc., Acad. Sci. USSR. 6: 133-157. (in Russian)

Kozhov, M. M., 1963. Lake Baikal and Its Life. Dr. W. Junk Publishers, The Hague.

Krausse, G. L., C. L. Schelske \& C. O. Davis, 1983, Comparison of three wet-alkaline methods of digestion of biogenic silica in water. Freshwat. Biol. 13: 73-81.

Leinen, M, 1977. A normative calculation technique for determining opal in deep-sea sediments. Geochim. Cosmochim. Acta 41: 671676.

Lipman, P. W., N. A. Logatchev, Yu. A. Zorin, C. E. Chapin, V. Kovalenko \& P. Morgan, 1989. Intercontinental rift comparisons. EOS Trans. Amer. Geophys. Union 70: 578-579, 586-587.

Logatchev, N. A., I. V. Antoshchenko-Olenev, B. B. Bazarov et al., 1974. The Highlands of the Baikal Region and Trans-Baikalia. Academy of Sciences, Moscow, 359 pp. (in Russian).

Lorefice, G. J. \& M. Munawar, 1974. The abundance of diatoms in the southwestern nearshore region of Lake Ontario during the spring thermal bar period. In: Proc. Seventeenth Conf. Great Lakes Res., Internat. Assoc. Great Lakes Res: 619-628.

Lund, J. W. G., 1966. The importance of turbulence in the periodicity of certain freshwater species of the genus Melosira. Bot. Zhur. 51: 176-187. (in Russian)

Mortlock, R. A. \& P. N. Froelich, 1989. A simple method for the rapid determination of biogenic opal in pelagic marine sediments. Deep-Sea Res. 36: 1415-1426.

Pilskaln, C. H., 1992. The sedimentation role of seasonal biogeochemical particle fluxes in Lakes Malawi and Baikal. EOS Trans. Amer, Geophys. Union 73: 197.

Pilskaln, C. H. \& J. B. Paduan, 1992. Laboratory techniques for the handling and geochemical analysis of water column particulate and surface sediment samples. MBARI Tech. Rept. No. 92-9, $22 \mathrm{pp}$.

Popovskaya, G. 1., 1991. Phytoplankton of Lake Baikal and its longterm changes (1958-1990). Dissertation Abstract: Academy of Sciences, Siberian Division, Central Siberian Botanical Garden, Novosibirsk, 32 pp. (in Russian)

Shimaraev, M. N., N. G. Granin \& A. A. Zhdanov, 1993. Deep ventilation of Lake Baikal waters due to spring thermal bar. Limnol. Oceanogr. 38: 1068-1072.

Skvortzow, B. W., 1937. Bottom diatoms from Olhon Gate of Lake Baikal, Siberia. Philipp. J. Sci. 62: 293-277.

Skvortzow, B. W. \& C. 1. Meyer, 1928. A contribution to the diatoms of Lake Baikal. Proc. Sungaree River Biological Sta. 12: 1-55.

Stoermer, E. F. 1975. Comparison of benthic diatom communities in Lake Michigan and Lake Superior. Verh. int. Ver. Limnol. 19: 932-938.

Stoermer, E. F., R. G. Kreis Jr. \& L. Sicko-Goad, 1981. A systematic, quantitative, and ecological comparison of two species of the diatom genus Melosira from the Laurentian Great Lakes. J. Great Lakes Res. 7: 345-356.

Stoermer, E. F., J. P. Kociolek, C. L. Schelske \& D. J. Conley, 1985a. Siliceous microfossil succession in the recent history of Lake Superior. Proc. Acad. Nat. Sci. Philadelphia 137: 106-118.

Stoermer, E. F., J. A. Wolin, C. L. Schelske \& D. J. Conley, 1985b. An assessment of ecological changes during the recent history of Lake Ontario based on siliceous microfossils preserved in the sediments. J. Phycol. 21:257-276.

Stoermer, E. F., J. A. Wolin, C. L. Schelske \& D. J. Conley, 1985c. Variations in Melosira islandica valve morphology in 
Lake Ontario sediments related to eutrophication and silica depletion. Limnol. Oceanogr. 30: 414-418.

Stoermer, E. F, Y.z. Qi \& T. B. Ladewski, 1986. A quantitative investigation of shape variation in Didymosphenia (Lyngb.) $\mathrm{M}$. Schmidt. Phycologia 25: 494-502.

Stoermer, E. F, C. L. Schelske \& J. A. Wolin, 1990. Siliceous microfossil succession in the sediments of McLeod Bay, Great Slave Lake, Northwest Territories. Can. J. Fish. Aquat. Sci. 47: 1865-1874.

Stoermer, E. F., J. A. Wolin \& C. L. Schelske, 1993. Paleolimnological comparison of the Laurentian Great Lakes based on diatoms. Limnol Oceanogr. 38: 1311-1316.
Thayer, V. L., T. C. Johnson \& H. J. Schrader, 1983. Distribution of diatoms in Lake Superior sediments. J. Great Lakes Res. 9: $508-516$.

Williams, D. F., L. Qui, E. Karabanov \& A. Gvozdkov. 1993. Geochemical indicators of productivity and sources of organic matter in surficial sediments of Lake Baikal. Geologiya i Geofizika 34: $111-125$.

Zorin, Yu. A., G. N. Glevskiy, V. A. Globev et al, 1977. An Outline of the Subsurface Structure of the Baikal Rift, Novosibirsk, $153 \mathrm{pp}$. 